\title{
Using SNP array data to test for host genetic and breed effects on Porcine Reproductive and Respiratory Syndrome Viremia
}

\author{
Stefano Biffani ${ }^{*^{* \dagger}}$, Sara Botti ${ }^{1 \dagger}$, Stephen C Bishop ${ }^{2}$, Alessandra Stella ${ }^{1,3}$, Elisabetta Giuffra ${ }^{1,4}$ \\ From International Symposium on Animal Genomics for Animal Health (AGAH 2010) \\ Paris, France. 31 May - 2 June 2010
}

\begin{abstract}
Background: The effect of breed on Porcine Reproductive and Respiratory Syndrome Viremia (PRRSV) was tested using data collected in 17 Italian commercial pig farms and 1096 genotypes obtained by the PorcineSNP60 BeadChip. A binomial logistic model was used to investigate the relationship between breed-clusters and PRRSV susceptibility. Breed-clusters were defined using the matrix of genomic kinship between all pairs of piglets.

Results: Only the contemporary group effect, defined as all piglets reared in the same herd, in the same year and whose samples were collected in the same season, was significant. Sex, age and breed-cluster showed no statistically significant effect on PRRS viremia, although the Landrace and Cross breed-clusters showed the lowest Odds-Ratio

Conclusions: The model failed to detect a significant breed-cluster effect, highlighting the impact of environment and management on PRRS viremia incidence. Incomplete exposure over the observed period may have masked possible breed differences.
\end{abstract}

\section{Background}

Over the last decade the genetics of host susceptibility/ resistance to disease has been a major topic of research. For the swine industry PRRS represents one of the most economically important diseases worldwide, causing reproductive failure, abortions, stillbirths, interstitial pneumonia and decreased growth rate [1]. Previous studies investigated the possible role which breed effect may have in determining resistant/susceptibility of pigs to PRRSV. One author [2] in an experimental "in vivo" study found difference between Duroc, Meishan and Hampshire while two authors [3,4] with an "in vivo" infection experiment using Large White/Landrace and Hamphshire/Duroc synthetic lines found the former being more resistant to the effects of the virus. Ait-Ali

\footnotetext{
* Correspondence: stefano.biffani@tecnoparco.org

+ Contributed equally

'Parco Tecnologico Padano-Loc. Cascina Codazza, Via A. Einstein, 26900 Lodi Italy

Full list of author information is available at the end of the article
}

et al[5] studied the innate immune response to PRRSV infection "in vitro", using used flow cytometry to analyse cells in bronchial alveolar lavage fluid (BALF) from five commercial pig lines. Macrophages from the Landrace line showed significantly reduced virus replication and poor growth of PRRSV than Large White, Pietrain and other two synthetic pig lines. Whilst "in vivo" and "in vitro" experiment can possibly help in dissecting PRRS pathogenesis among breeds, these studies were usually based on relatively small numbers of animals. Moreover, they do not consider environment and management which actually play an important role in the host resistant/susceptibility to PRRSV. Using data collected in commercial pig farms and genotypes obtained by the PorcineSNP60 BeadChip (Illumina, San Diego, CA), the objective of the present study was to cluster animals based on the average similarity among them and to test a possible breed-cluster effect on PRRS viremia.

(c) 2011 Biffani et al; licensee BioMed Central Ltd. This is an open access article distributed under the terms of the Creative Commons 


\section{Methods}

The data for the present study were extracted from an existing database belonging to the MISAGEN project [6], which included pedigree information, clinical symptoms, and health related phenotypes collected from a commercial pig breeding population in the north of Italy. The original dataset included records for the PRRS viremia measured by PCR in sera of 2908 weaning piglets from four breeds, namely LargeWhite, Landrace, Duroc and Pietrain. PRRS viremia was defined as a binary trait based on the results of the traditional PCR: negative samples were coded as 0 , positive samples as 1 . DNA samples from 1,096 piglets were genotyped for 64,232 SNPs using the PorcineSNP60 BeadChip [7]. Negative and positive piglets numbered 766 and 440 animals, respectively. The number of negative/positive piglets by breed is shown in table 1 . Prior to statistical analyses genotype quality control was performed using the quality control function implemented in the GenABEL package for $\mathrm{R}$ statistical software [8]. The following filters were applied for exclusion of individual single nucleotide polymorphisms (SNPs):

- call-rate (\%) < 99 (if the SNP was available in less than $99 \%$ of all genotyped individuals)

- minor allele frequency (MAF) in all individuals $<0.05$

Furthermore individuals $<99 \%$ call rate (maximum percent of missing genotypes in an individual) were eliminated. A total of 14,967 SNPs (24.8\%), from the available 60,123 SNPs, were excluded from the case-control analysis if one of the filters indicated a violation of the quality. A total of $77(0.063 \%)$ individuals were excluded: 33 individuals who had low call rates, 3 individuals with too high Identity By State (IBS) and 41 individuals with sex discrepancies. A contemporary group (Herd-Year-Season, HYS) was defined as all piglets reared in the same herd, in the same year and whose samples were collected in the same season. Sampling season was categorized as season 1 (January to April), season 2 (May to August) and season 3 (September to December). Totally, 46 HYS groups were defined whose average size was 9.1. Three breeds were present in twenty HYS (43\%), two breeds in sixteen HYS (35\%), four breeds in three HYS (15\%) and only one breed in seven HYS (15\%). A General Linear Mixed Model with

Table 1 Number of negative (0) and positive (1) piglets by breed (original dataset)

\begin{tabular}{cccc}
\hline Breed & $\mathbf{0}$ & $\mathbf{1}$ & \% Infected \\
\hline Duroc & 189 & 137 & $42 \%$ \\
Landrace & 134 & 67 & $33 \%$ \\
Large White & 309 & 207 & $40 \%$ \\
Pietrain & 24 & 29 & $55 \%$ \\
\hline Total & 656 & 441 & $40 \%$ \\
\hline
\end{tabular}

a logit link function and binomial distributions was used to investigate the relationship between breed and PRRSV susceptibility using the Glimmix procedure in SAS version 9.1 (SAS Institute Inc., Cary, NC). Breedclusters were defined using the matrix of genomic kinship between all pairs of piglets computed as:

$$
i b s_{i, j}=\frac{1}{L} \sum_{l=1}^{L} \frac{\left(g_{l, i}-p_{l}\right)\left(g_{l, j}-p_{l}\right)}{p_{l}\left(1-p_{l}\right)} \text {, where } \mathrm{L} \text { is the }
$$

number of loci, $\mathrm{p}_{1}$ is the allelic frequency at 1-th locus and $g_{1 ; j}$ is the genotype of $j$-th individual at the 1-th locus, coded as $0,1=2$, and 1 , corresponding to the homozygous, heterozygous, and other type of homozygous genotype. Such a matrix was transformed to a distance matrix and the first two principal components were computed by Classical Multidimensional Scaling. The fitted model was: $Y_{i j k l}=H Y S_{i}+G_{j}+B_{k}+F_{l}+b$. $a g e_{l}+e_{i j k l}(1)$, where $\mathrm{Y}$ is the binary trait, HYS is the fixed effect of the ith contemporary group, $G$ is the fixed effect of jth gender class, $B$ is the fixed effect of the kth breed-cluster class, $F$ is the random effect of lth piglet, age is the covariate for age at sampling, with $b$ being the regression coefficient, and $\mathrm{e}$ is the random error.

\section{Results}

Breed-clusters as a result of "a posteriori" definition based on Kinship analysis are plotted in Figure 1. Each point represents a piglet. As expected, using SNP information, four main clusters can be identified. Those clusters matched with the expected breed, defined by the time of field data recording. However, an additional cluster (cluster 4 ) can be identified between cluster 1

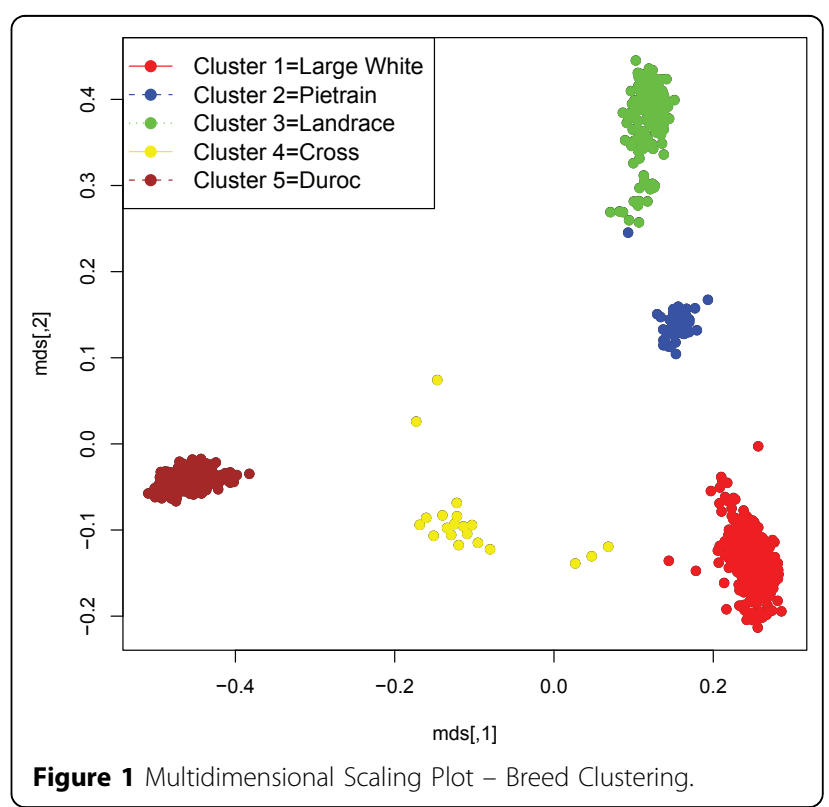


Table 2 Number of negative (0) and positive (1) piglets by breed-cluster (after SNP editing)

\begin{tabular}{cccc}
\hline Breed-Cluster & $\mathbf{0}$ & $\mathbf{1}$ & \% Infected \\
\hline 1 (Large White) & 271 & 182 & $40 \%$ \\
2 (Pietrain) & 26 & 28 & $52 \%$ \\
3 (Landrace) & 121 & 63 & $34 \%$ \\
4 (Cross) & 10 & 10 & $50 \%$ \\
5 (Duroc) & 180 & 128 & $42 \%$ \\
\hline Total & 608 & 412 & $40 \%$ \\
\hline
\end{tabular}

(Large White) and cluster 5 (Duroc). Those animals are possibly the result of cross-breeding. Indeed, they belong to farms where both breeds (i.e, Large White and Duroc) were present and where artificial insemination was used. Our hypothesis is that some inconsistencies occurred during the insemination events, i.e. that a limited number of boars was associated to the wrong insemination. According to the breed-cluster classification (Table 2), the observed proportion of affected piglets ranges from 34\% (Landrace - Cluster 3) to 52\% (Pietrain - Cluster 2). Results from Type III test of fixed effects are shown in table 3. Only the Herd-Year-Season effect (contemporary group) is significant. Sex, age and breed-cluster show no statistically significant effect on PRRS viremia, although the Landrace and Cross clusters show the lowest Odds-Ratio (not shown). Results on breed-cluster effect are contradictory. Some studies reported the existence of differences in susceptibility among breeds $[9,10]$. Nevertheless, most of those studies were based on in vitro or in vivo experiments, used commercial data from few large farms or analyzed different phenotypes. The present study spanned a 3-year period and used data collected from 17 farms. As Cooper et al. [11] observed, data under controlled experimental conditions do not necessarily support field reports. Physical and environmental factors may affect the immune system and hence determine or change the host response. This is exactly what our results suggest, because the contemporary group effect tries to capture the combined effect of environment and management removing variation due to their conditions over time. Previous findings from MISAGEN data [12] do show the existence of genetic variation but no breed effect. In this case breed was not defined by Kinship analysis. Bishop and Woolliams [13] showed how incomplete exposure to infection

Table 3 Type III text of fixed effects of breed, age, HYS and sex

\begin{tabular}{lcccc}
\hline Effect & Num DF & Den DF & F Value & Pr $>$ F \\
\hline Breed-Cluster & 4 & 317.6 & 0.91 & 0.4597 \\
age & 1 & 651.7 & 0.24 & 0.6216 \\
hyseason & 45 & 172.5 & 1.9 & 0.0018 \\
sex & 1 & 967 & 0 & 0.9815 \\
\hline
\end{tabular}

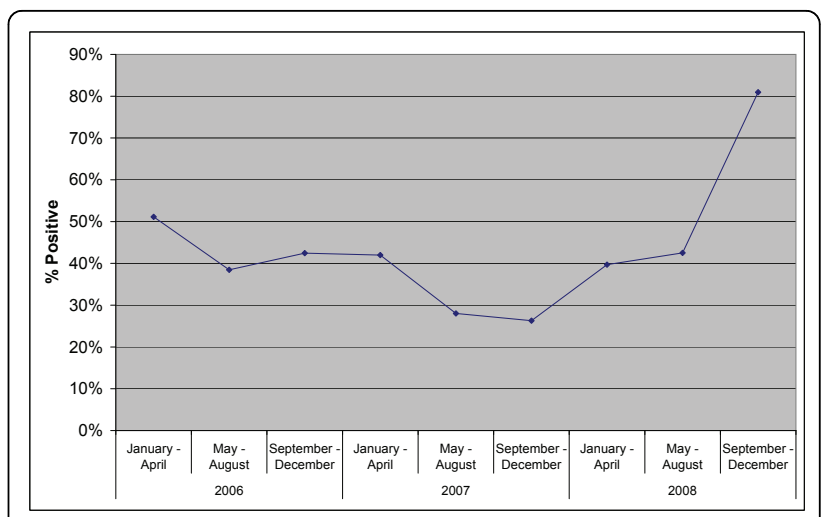

Figure 2 Observed PRRS viremia incidence over the test period.

can reduce the power of datasets. This is the case of the present study, where records were collected in commercial farms spanning a 3-year period. As can be observed in Figure 2 incidence varies from a minimum of $27 \%$ (September - December 2007) to a maximum of $80 \%$ (September - December 2008).

\section{Conclusions}

The idea behind this study was to use SNP to correctly cluster animals based on the average similarity among them and to test a possible breed-cluster effect using a General Linear Mixed model. The model fails to detect a significant breed-cluster effect but highlighted the impact of environment and management on PRRS viremia incidence. Although we cannot formally exclude that incomplete exposure over the observed period may have masked possible breed differences, the genome wide analysis currently in progress could detect a significant genetic variability in host response to PRRSV in the same dataset (Botti, Biffani et al. in preparation).

\section{Acknowledgements}

This study was supported by the MISAGEN project (DG Agriculture of Lombardia Region), the ProZOO project (Cariplo Foundation and DG Agriculture of Lombardia Region ) and SABRE (http://www.sabre-eu.eu, demonstration projects grant (SCAN-IT).

This article has been published as part of BMC Proceedings Volume 5 Supplement 4, 2011: Proceedings of the International Symposium on Animal Genomics for Animal Health (AGAH 2010). The full contents of the supplement are available online at http://www.biomedcentral.com/1753$6561 / 5$ ? issue $=$ S4

\section{Author details}

'Parco Tecnologico Padano-Loc. Cascina Codazza, Via A. Einstein, 26900 Lodi Italy. ${ }^{2}$ The Roslin Institute and R(D)SVS, University of Edinburgh, Roslin, Midlothian EH25 9PS Scotland, UK. Instituto di Biologia e Biotecnologia Agraria - CNR, Loc. Cascina Codazza, Via A. Einstein, 26900 Lodi, Italy. ${ }^{4}$ Current address: INRA, UMR 1313 de Génétique Animale et Biologie Intégrative, Jouy-en-Josas, France - and - AgroP arisTech, UMR 1313 de Génétique Animale et Biologie Intégrative, Jouy-en-Josas, France.

\section{Authors' contributions}

STB and SAB wrote the manuscript. STB performed the statistical analysis and interpretation of data. SAB designed and coordinated the acquisition of 
genotypic and phenotypic data. SCB contributed to design and interpretation of data and critically revised the manuscript. ALS contributed to design and supervised the statistical analysis. ELG conceived of the study and coordinated it.

All authors read, revised and approved the final manuscript.

\section{Competing interests}

The authors declare that they have no competing interests.

Published: 3 June 2011

\section{References}

1. Neumann EJ, Kliebenstein JB, Johnson CD, Mabry JW, Bush EJ, Seitzinger AH, Green AL, Zimmerman JJ: Assessment of the economic impact of porcine reproductive and respiratory syndrome on swine production in the US. J. Am. Vet. Med. Assoc. 2005, 227:385-392.

2. Halbur PG, Rothschild MF, Thacker BJ, Meng XJ, Paul PS, Bruna JD Differences in susceptibility of Duroc, Hamsshire, and Meishan pigs to infection with a high virulence strain (VR2385) of porcine reproductive resiratory syndrome virus (PRRSV). J. Anim. Breed. Genet. 1998, 115:181-189.

3. Petry DB, Holl JW, Weber JS, Doster AR, Osorio FA, Johnson RK: Biological responses to porcine respiratory and reproductive syndrome virus in pigs of two genetic populations. J Anim Sci 2005, 83:1494-502.

4. Petry DB, Lunney J, Boyd P, Kuhar D, Blankenship E, Johnson RK: Differential immunity in pigs with high and low responses to porcine reproductive and respiratory syndrome virus infection. J Anim Sci 2007, 85:2075-92.

5. Ait-Ali T, Wilson AD, Westcott DG, Clapperton M, Waterfall M, Mellencamp MA, Drew TW, Bishop SC, Archibald AL: Innate immune responses to replication of porcine reproductive and respiratory syndrome virus in isolated Swine alveolar macrophages. Viral Immunol 2007, 20:105-18.

6. Botti S, Caprera A, Gaita L, Mondin P, Ossani N, Palermo S, Luini M, Vezzoli F, Cordioli P, Nigrelli P, Fallacara C, Barbieri I, Pacciarini M, Bandi C, Stella A, Giuffra E: The misagen project: towards the genetic improvement of disease resistance of pig commercial populations. Proceedings 8th WCGALP 2006, 26:414-417.

7. Ramos AM, Crooijmans RPMA, Affara NA, Amaral AJ, Archibald AL, et al: Design of a High Density SNP Genotyping Assay in the Pig Using SNPs Identified and Characterized by Next Generation Sequencing Technology. PLOS ONE 2009, 4(8):e6524, doi:10.1371/journal.pone.0006524

8. Aulchenko YS, Ripke S, Isaacs A, van Duijn CM: GenABEL: an R library for genome-wide association analysis. Bioinformatics 2007, 23:1294-1296.

9. Lewis CR, Torremorell M, Galina-Pantoja L, Bishop SC: Genetic parameters for performance traits in commercial sows estimated before and after an outbreak of porcine reproductive and respiratory syndrome. J Anim Sci 2009, 87:876-84.

10. Reiner G, Willems H, Pesch S, Ohlinger VF: Variation in resistance to the porcine reproductive and respiratory syndrome virus (PRRSV) in Pietrain and Miniature pigs. J Anim Breed Genet 2010, 127:100-6.

11. Cooper VL, Doster AR, Hesse RA, Harris NB: Porcine reproductive and respiratory syndrome: NEB-1 PRRSV infection did not potentiate bacterial pathogens. J Vet Diagn Invest 1995, 7:313-20.

12. Biffani S, Botti S, Caprera A, Giuffra E, Stella A: Genetic Susceptibility to Porcine Reproductive and Respiratory Syndrome (PRRS) virus in commercial pigs in Italy. Proceedings 9th WCGALP .

13. Bishop SC, Woolliams JA: On the genetic interpretation of disease data. PLoS One 2010, 5(1):e8940.

\section{doi:10.1186/1753-6561-5-S4-S28}

Cite this article as: Biffani et al:: Using SNP array data to test for host genetic and breed effects on Porcine Reproductive and Respiratory Syndrome Viremia. BMC Proceedings 2011 5(Suppl 4):S28.

\section{Submit your next manuscript to BioMed Central and take full advantage of:}

- Convenient online submission

- Thorough peer review

- No space constraints or color figure charges

- Immediate publication on acceptance

- Inclusion in PubMed, CAS, Scopus and Google Scholar

- Research which is freely available for redistribution

Submit your manuscript at www.biomedcentral.com/submit
Ciomed Central 